University of Wollongong

Research Online

Faculty of Engineering and Information

Faculty of Engineering and Information

Sciences - Papers: Part A

Sciences

$1-1-2014$

\title{
Water reclamation from shale gas drilling flow-back fluid using a novel forward osmosis-vacuum membrane distillation hybrid system
}

\author{
Xue-Mei Li \\ Chinese Academy of Sciences \\ Baolong Zhao \\ Chinese Academy of Sciences \\ Zhongwei Wang \\ Chinese Academy of Sciences, zw702@uowmail.edu.au \\ Ming Xie \\ University of Wollongong, mx504@uowmail.edu.au \\ Jianfeng Song \\ Chinese Academy of Sciences
}

See next page for additional authors

Follow this and additional works at: https://ro.uow.edu.au/eispapers

Part of the Engineering Commons, and the Science and Technology Studies Commons

Research Online is the open access institutional repository for the University of Wollongong. For further information contact the UOW Library: research-pubs@uow.edu.au 


\title{
Water reclamation from shale gas drilling flow-back fluid using a novel forward osmosis-vacuum membrane distillation hybrid system
}

\begin{abstract}
This study examined the performance of a novel hybrid system of forward osmosis (FO) combined with vacuum membrane distillation (VMD) for reclaiming water from shale gas drilling flow-back fluid (SGDF). In the hybrid FO-VMD system, water permeated through the FO membrane into a draw solution reservoir, and the VMD process was used for draw solute recovery and clean water production. Using a SGDF sample obtained from a drilling site in China, the hybrid system could achieve almost $90 \%$ water recovery. Quality of the reclaimed water was comparable to that of bottled water. In the hybrid FO-VMD system, FO functions as a pre-treatment step to remove most contaminants and constituents that may foul or scale the membrane distillation (MD) membrane, whereas MD produces high quality water. It is envisioned that the FO-VMD system can recover high quality water not
\end{abstract}

\section{Keywords}

distillation, back, flow, fluid, membrane, novel, water, reclamation, shale, forward, gas, drilling, osmosis, system, hybrid, vacuum

\section{Disciplines \\ Engineering | Science and Technology Studies}

\section{Publication Details}

Li, X., Zhao, B., Wang, Z., Xie, M., Song, J., Nghiem, L. D., He, T., Yang, C., Li, C. \& Chen, G. (2014). Water reclamation from shale gas drilling flow-back fluid using a novel forward osmosis-vacuum membrane distillation hybrid system. Water Science and Technology, 69 (5), 1036-1044.

\section{Authors}

Xue-Mei Li, Baolong Zhao, Zhongwei Wang, Ming Xie, Jianfeng Song, Long Nghiem, Tao He, Chi Yang, Chunxia Li, and Ghang Chen 


\section{Water reclamation from shale gas drilling flow-back fluid using a novel forward osmosis (FO) - vacuum membrane distillation (VMD) hybrid system}

\section{Water Science and Technology}

Revised: $14^{\text {th }}$ November 2013

Xue-Mei Li ${ }^{1}{ }^{1, *}$, Baolong Zhao ${ }^{1}$, Zhouwei Wang ${ }^{1}$, Ming Xie ${ }^{2}$, Jianfeng Song ${ }^{1}$, Long D. Nghiem $^{2}$, Tao $\mathrm{He}^{1, *}$, Chi Yang ${ }^{1}$, Chunxia $\mathrm{Li}^{1}$, and Gang Chen ${ }^{1}$

${ }^{1}$ Membrane Materials and Separation Technology, Shanghai Advanced Research Institute, Chinese Academy of Sciences, Shanghai, China

${ }^{2}$ Strategic Water Infrastructure Laboratory, School of Civil, Mining and Environmental Engineering, University of Wollongong, Wollongong, NSW 2522, Australia

* Corresponding authors: Xue-Mei Li(lixm@sari.ac.cn), Tao He (het@sari.ac.cn); Ph +862120325162 


\section{Abstract}

This study examined the performance of a novel hybrid forward osmosis (FO) vacuum membrane distillation (VMD) system for reclaiming water from shale gas drilling flow-back fluid (SGDF). In the hybrid FO-VMD system, water permeated through the FO membrane into a draw solution reservoir and the VMD process was used for draw solute recovery and clean water production. Using SGDF sample obtained from a drilling site in China, the hybrid system could achieve almost $90 \%$ water recovery. Quality of the reclaimed water is comparable to that of bottled water. In the hybrid FO-VMD system, FO functions as a pre-treatment step to remove most contaminants and constituents that may foul or scale the MD membrane, whereas MD produces high quality water. It is envisioned that the FO-VMD system can recover high quality water not only from SGDF but also other wastewaters with high salinity and complex compositions.

Key words : water reclamation; water reuse; forward osmosis; shale gas; drilling and fracturing fluid; membrane distillation. 


\section{Introduction}

Hydraulic fracturing of oil and gas wells has attracted significant attention for contributing toward energy security as well as potential environmental impact (Shaffer et al. 2013). Hydraulic fracturing is a water intensive process (Dahm et al. 2011) and can produce a large volume of saline wastewater known as shale gas drilling flow-back fluid (SGDF) which can account for 30 to $70 \%$ of the original fracturing fluid volume. SGDF contains various dissolved constituents including organic matters and inorganic salts. The treatment of the SGDF is a major challenge for the oil and gas industry because of the stringent regulations and discharge limits (Hickenbottom et al. 2012).

Several techniques can be used for the treatment and disposal of SGDF including deep well injection, thermal evaporation-distillation, and reverse osmosis ( $\mathrm{Xu} \&$ Drewes 2006; Xu et al. 2008). Deep well injection permanently eliminates the water from water cycle, while the treatment cost associated with the other techniques are high due to high energy consumption or fouling/scaling. Therefore, the development of novel treatment processes to manage SGDF is essential for the oil and gas industry. Recently, forward osmosis (FO) technology has been pursued as an alternative for the treatment of SGDF. FO is an osmotically driven membrane process. During the FO process, water diffuses spontaneously from a stream of low osmotic pressure (the feed solution) to a hypertonic (draw) solution having a very high osmotic pressure through a semipermeable membrane (Cath et al. 2006). Hickenbottom et al (2012) successfully demonstrated an osmotic dilution process for the treatment of drilling mud with a water recovery of up to $80 \%$, where the diluted draw solution was utilized directly as the 
fracturing fluid reducing the fresh water demand in the hydraulic fracturing process. Osmotic dilution has shown considerable advantages in minimal energy input without the recovery of draw solute.

To reclaim water from SGDF, McGinnis et al (2013) has constructed an FO membrane brine concentrator (FO-MBC) pilot system using $\mathrm{NH}_{3} / \mathrm{CO}_{2}$ as the draw solution. In their FO-MBC system, clean water was recovered by heat treatment of the draw solution, which showed much less energy demand than a conventional evaporator. We have reported a concept of FO integrated membrane distillation (MD) process for water recovery from synthetic high salinity water with TDS of $10 \mathrm{wt} \%$, where the FO process concentrates the feed water and MD claimed fresh water from the diluted draw solution (He 2012). The advantages of FO, especially fouling resistant, rejection towards organic matters, and the capability of MD to treatment of high TDS are shown. Moreover, because the feed to the MD process is pre-treated by FO, membrane fouling and scaling can be managed, and thus the integrated process is promising in the treatment of wastewaters with high salinity and fouling propensity. Although the integrated FO-MD processes have been demonstrated for treatment of various forms of wastewater (Cath et al. 2005a; Cath et al. 2005c; Yen et al. 2010; Wang et al. 2011; Ge et al. 2012), to date, their application for treating SGDF has not been reported.

Currently, there is a lack technical guideline and regulations in China in terms of SGDF management (Tong et al. 2013). More concerning, most shale gas drilling sites are located in densely populated southwest China (e.g. Sichuan, Chongqing, and Guizhou) where water crisis could be further exacerbated (Chang et al. 2012). 
In this paper, a systematic study on the hybrid process for water reclamation is reported using SGDF from a mining site at the southwest China. Commercially available FO membranes were used in the FO process. The FO process was optimized with respect to the selection of draw solutes and operation conditions. A vacuum membrane distillation MD process was applied for draw solution recovery. The product water quality and the feed wastewater quality were analysed to assess the feasibility of the integrated process for the treatment of highly complicated feed wastewater streams.

\section{Materials and Methods}

\subsection{Membranes and Chemicals}

An asymmetric, cellulose triacetate membrane from Hydration Technology Innovations (Albany, OR) was used for the FO process. The FO membrane, embedded in a polyester mesh for mechanical support, has a dense, moderately hydrophilic cellulose triacetate active layer. More details on the FO membrane are provided elsewhere (Cath et al. 2006;McCutcheon \& Elimelech 2008). A CF 4-plasma modified polyvinylidene fluoride (PVDF, Millipore $0.22 \mu \mathrm{m}$ GVHP) microporous membrane was used for the VMD process. SGDF sample was collected from a drilling field in southwest China. Analytical grade sodium chloride (NaCl, CAS No.: 7647-14-5), potassium chloride (KCl, CAS No.: 7447-40-7) and magnesium chloride ( $\mathrm{MgCl}_{2}$, CAS No.: 7791-18-6) acquired from Sinopharm Chemical Reagent (Shanghai, China) were used as draw solutes in the FO process. 


\subsection{Pre-treatment of SGDF}

Pre-treatment of SGDF was conducted to remove suspended particles, including coagulation and ultrafiltration. Two types of coagulants $\left(\mathrm{AlCl}_{3} \cdot 6 \mathrm{H}_{2} \mathrm{O}\right.$ and $\left.\mathrm{FeCl}_{3} \cdot 6 \mathrm{H}_{2} \mathrm{O}\right)$ were assessed at various concentrations and sedimentation time (mixing and sediment). SGDF after coagulation was ultra-filtered by a polyethersulfone hollow fiber membrane with molecular weight cut-off of $70 \mathrm{kDa}$ (Altrateck, Nanjing, China) (Song et al. 2013). After the pre-treatment, the SGDF was further treated by an FO-VMD hybrid system.

\subsection{FO-VMD hybrid system}

A lab-scale flat-sheet cross-flow FO-VMD setup was employed to treat the SGDF after coagulation and ultrafiltration (Figure 1).The length, width and depth of the FO membrane cell were 100, 30 and $4 \mathrm{~mm}$, respectively. Two variable speed gear pumps were used to circulate the feed and draw solutions concurrently. Flow rates of the feed and draw solutions were monitored with rotameters and kept constant at $0.6 \mathrm{~L} / \mathrm{min}$. Temperatures of both feed and draw solutions were controlled using thermostatic bath.

Water flux, $J_{w}$, was determined as the weight change $(\Delta W)$ of the feed solution at a certain time interval $(\Delta t)$ at unit membrane area $(A)$.

$$
J_{w}=\frac{\Delta W}{A \Delta t}
$$

Reverse draw solute flux, $J_{s}$, was determined using mass balance calculation:

$$
J_{s}=\frac{\left(C_{t} V_{t}-C_{0} V_{0}\right)}{A t}
$$


where $C_{0}$ and $C_{\mathrm{t}}$ are the concentrations of the draw solute in the feed at time 0 and $t$, respectively; $V_{0}$ and $V_{\mathrm{t}}$ are the volumes of the feed at time 0 and $t$, respectively; $A$ is the membrane area, and $t$ is the operating time of the FO experiment.

Prior to the operation of the FO-VMD hybrid system, this FO unit was employed to assess the treatment efficiency of SGDF by varying key parameters, including type and concentration of draw solution, temperature and cross-flow velocity of feed and draw solution, and membrane orientation. Each type of draw solution was used separately to evaluate and compare the process efficiency by the FO unit.

For VMD unit, dimensions of the VMD membrane cell were $100 \mathrm{~mm}$ in length, 30 $\mathrm{mm}$ in width and $4 \mathrm{~mm}$ in depth, respectively. A diamond shape spacer was used to prevent the deformation of the $\mathrm{CF}_{4}$-modified PVDF membrane (Wei et al. 2012). The vacuum pressure for distillate side was - $40 \mathrm{kPa}$ and sweeping air was used at a flow rate of $6.0 \mathrm{~L} / \mathrm{min}$ to facilitate water condensation at the distillate side. To reduce the energy consumption for heating draw solution (3 L in the FO unit), an overflow design was used to connect the FO and VMD units in this hybrid system. Specifically, only a small amount of draw solution (500 mL) was heated and concentrated in the VMD unit, and then the concentrated draw solution was overflew to the draw solution tank in the FO unit. Basic performance of the FO-VMD hybrid system, including water permeate flux, temperature, vacuum pressure and electrical conductivity of the product water, was recorded by a data logger.

\section{[Figure 1]}




\subsection{Water quality analysis}

Basic water parameters (including $\mathrm{pH}$, electric conductivity, turbidity, total hardness, chemical oxygen demand (COD) and ammonia)of the SGDF sample before and after pre-treatment and product water were tested following standard methods. Ions concentrations were determined by an Inductively Coupled Plasma - Atomic Emission Spectrometry (ICP-AES) (ICPE-9000, Shimadzu, Kyoto) and an Ion Chromatography (LC20AT, Shimadzu, Kyoto), respectively. The ICP-AES utilises the wavelength and intensity of electromagnetic emission to determine the concentration of each target element. Calibration was conducted prior to each batch of analysis. The linear regression coefficients $\left(R^{2}\right)$ for all calibration curves were greater than 0.99 . Osmotic pressure of varying draw solutions were analysed by an osmometer (Osmomat 030, Gonotec GmbH, Germany) using freezing point method.

\section{Results and Discussion}

\subsection{Pre-treatment of SGDF}

Systematic analysis showed that SGDF was highly saline with total dissolve solid (TDS) of $6700 \mathrm{mg} / \mathrm{L}$. NaCl was the dominant inorganic salt with concentration of 2072 mg/L in the SGDF sample. The organic matter was also significant with COD of 259 $\mathrm{mg} / \mathrm{L}$.

Pre-treatment using coagulation and ultrafiltration was effective to remove colour, suspended particles and some soluble contaminants, thereby improving feed water 
quality before FO-VMD treatment (Table 1). Specifically, the initial SGDF was

yellowish and turbid, and after pre-treatment with coagulation (80 $\mathrm{mg} / \mathrm{LFeCl}_{3} \cdot 6 \mathrm{H}_{2}$ Oand 30 min sedimentation) and ultrafiltration, the pre-treated SGDF became clear and transparent.TDS removal by coagulation and UF pre-treatment was negligible as expected. However, COD removal was 25\% and the removal of Si, Sr, and Ca was in the range of 20 to $40 \%$.

\section{[Table 1]}

\subsection{SGDF treatment efficiency by FO}

\subsubsection{Types of Draw solution}

Water fluxes induced by $\mathrm{KCl}, \mathrm{NaCl}$ and $\mathrm{MgCl}_{2}$ were compared in $\mathrm{FO}$ mode (i.e., membrane active layer contacts feed solution). To minimise the impact on the permeate flux caused by the dilution of the draw solution, the operating time for each experiment was 30 min (corresponding to a cumulative permeate volume of $80 \mathrm{~mL}$ ). To produce the same osmotic pressure of $180 \mathrm{~atm}$, the required concentrations of $\mathrm{KCl}, \mathrm{NaCl}$ and $\mathrm{MgCl}_{2}$ are 3, 3.26, and $1.75 \mathrm{M}$, respectively (Figure 2a). However, at the same osmotic pressure of $180 \mathrm{~atm}$, the water flux in $\mathrm{FO}$ mode was in the order of $\mathrm{KCl}>\mathrm{NaCl}>\mathrm{MgCl}_{2}$ (Figure 2b). This order of water flux is mainly driven by the effective diffusion coefficient of the draw solutes when the osmotic pressures of three draw solutions were the same(Lay et al. 2012). In fact, diffusion coefficients of three draw solutes were in the same order as water fluxes, namely, $\mathrm{KCl}>\mathrm{NaCl}>\mathrm{MgCl}_{2}$ (Tang \& $\mathrm{Ng} 2008$; Xu et al. 2010; Lay et al. 2012). 
Reverse salt flux selectivity (RSFS), $J_{w} / J_{s}$, was determined by properties of membrane active layer (water and draw solute permeabilities) and thermodynamic properties of draw solutions (osmotic pressure) (Phillip et al. 2010; Xie et al. 2013c). The RSFS can be considered as the volume of water produced per the moles (or mass) of draw solute lost, which is an important parameter to evaluate the draw solution efficiency in an FO process. The RSFS of three draw solutions were in the order of $\mathrm{MgCl}_{2}>\mathrm{NaCl}>\mathrm{KCl}$ (Figure 2b), which was consistent with their diffusion coefficients. This is because under the same draw solution osmotic pressure (i.e., $180 \mathrm{~atm}$ ), the RSFS is related to the membrane solute permeability or solute diffusivity (Phillip et al. 2010; Xie et al. 2013c).

\section{[Figure 2]}

\subsubsection{Draw solution concentration and key operating conditions}

Water flux increased significantly as the feed and draw solution temperature increased from 15 to $45^{\circ} \mathrm{C}$ (Figure 3a). This thermally-induced increase in water flux was largely driven by the increase in water and $\mathrm{KCl}$ diffusivities at an elevated temperature (Phuntsho et al. 2012; Xie et al. 2013c).

Water flux increased as the draw solution concentration increased, as expected (Figure 3b). However, it is noteworthy that increase in water flux was non-linear when the draw $\mathrm{KCl}$ solution concentration was beyond $2.5 \mathrm{M}$. This water flux behaviour is mainly ascribed to dilutive internal concentration polarization where the draw solution in porous support layer was diluted by the permeate, thereby reducing the effective 
osmotic pressure difference across the membrane (McCutcheon \& Elimelech 2006; Xie et al. 2013c).

There was negligible difference in water flux as the cross-flow rate increased from 0.5 to $2 \mathrm{~L} / \mathrm{min}$ (Figure 3c). Despite the increase in Reynolds number from 578 to 2312, water flux was largely unchanged, indicating that the external concentration polarization was insignificant (McCutcheon \& Elimelech 2007). This result was consistent with a previous study by Kim et al (2012).

\section{[Figure 3]}

\subsubsection{Membrane orientation}

FO membrane could be operated in either FO mode (i.e., active layer faced feed solution) or PRO mode (i.e., active layer faced draw solution). Water flux behaviour was significantly different under two membrane orientations (Figure 4). Water flux was stable at $22 \mathrm{~L} / \mathrm{m}^{2} \mathrm{~h}$ in the FO mode; whereas water flux decline gradually from 30 to 12 $\mathrm{L} / \mathrm{m}^{2} \mathrm{~h}$ in the PRO mode. Water flux in the PRO mode was higher than that in the FO mode at the initial stage. Specifically, the dilutive internal concentration polarization in the FO mode is more pronounced than concentrative internal concentration polarization in the PRO mode, which substantially reduces the effective osmotic driving force for water flux (Xie et al. 2012). In addition, the gradual decline in water flux in the PRO mode could be attributed to the build-up of membrane fouling in the porous support layer (Tang et al. 2010; Liu et al. 2011; Zhao \& Zou 2011; Zhao et al. 2011; Jin et al. 2012). In the PRO mode, foulants in the SGDF were trapped in the porous support layer 
and led to sever internal concentration polarization, thereby substantially decreasing water flux. Indeed, a brownish fouling layer was observed at the conclusion of the PRO experiment. By contrast, in the FO mode, membrane fouling was insignificant due to the absence of trans-membrane hydraulic pressure (Xie et al. 2013b), thereby leading to a stable water flux. These results highlighted that FO mode performed better than PRO mode in treating feed solution with high fouling propensity.

In summary, SGDF treatment efficiency by the FO process was better when the FO mode was used. Thus, the FO mode was used in the FO-VMD hybrid system for SGDF treatment. In addition, draw solution was $3 \mathrm{M} \mathrm{KCl,} \mathrm{cross-flow} \mathrm{rates} \mathrm{and} \mathrm{temperatures}$ for both feed and draw solutions were $0.5 \mathrm{~L} / \mathrm{min}$ and $30^{\circ} \mathrm{C}$, respectively.

\section{[Figure 4]}

\subsection{SGDF treatment efficiency by FO-VMD hybrid process}

The FO-VMD hybrid process was employed to reclaim freshwater from SGDF. In this hybrid system, freshwater in the pre-treated SGDF was first extracted into $3 \mathrm{M} \mathrm{KCl}$ draw solution by FO process and then was produced by VMD process. At the same time, the diluted draw solution was concentrated and re-circulated back to the FO process. Comparing to similar design in previous studies (Cath et al. 2005b; Altaee et al. 2013), the unique design in the FO-VMD was that a draw solution over-flow connection allowed for only heating a small volume of the draw solution in VMD process, thereby substantially reducing the energy consumption and carbon footprint of the FO-VMD system. 
Water flux in the FO process was stable at $18 \mathrm{~L} / \mathrm{m}^{2} \mathrm{~h}$ during 15 hours of operation, reaching water recovery of $88 \%$. It is noteworthy that water flux was fully restored to the initial one after draw $\mathrm{KCl}$ solution was replenished after 4.25 hour of operation (Figure 5a). This suggests that membrane fouling by SGDF was insignificant during the FO process and the decrease in water flux could be largely attributed to the concentration of feed SGDF solution and the dilution of draw $\mathrm{KCl}$ solution.

Different approaches were applied to enhance the water flux in VMD process, including sweeping air, elevated feed solution temperature and enhanced vacuum pressure (Figure 5b). Unfavourable water condensation happened in the VMD membrane module and distillation side tubings (designate as “a” in Figure 5b), which resulted in unstable water flux in VMD process. To enhance the water flux, a sweeping air was used in the distillate side at a flow rate of $6 \mathrm{~L} / \mathrm{min}$ (designate as "b" in Figure 5b). The sweeping air significantly enhanced the water flux from 12 to $16 \mathrm{~L} / \mathrm{m}^{2} \mathrm{~h}$. In addition, elevated feed solution temperature from 59 to $65^{\circ} \mathrm{C}$ led to a substantial increase in water flux from 16 to $24 \mathrm{~L} / \mathrm{m}^{2} \mathrm{~h}$ (designate as “c” in Figure 5b). Furthermore, water flux increased from 16 to $19 \mathrm{~L} / \mathrm{m}^{2} \mathrm{~h}$ when the vacuum pressure increased from -40 to $-58 \mathrm{kPa}$ (designate as “d” in Figure 5b).

\section{[Figure 5]}

Product water quality from FO-VMD hybrid process was indicated by its gradual conductivity decline from 7.5 to $3 \mu \mathrm{S} / \mathrm{cm}$ (Figure 5b). More importantly, there was negligible difference between product water and retail bottle drinking water in terms of basic water quality parameters and inorganic substances (Table 1). Such high product 
water quality by the FO-VMD process was largely attributed to near complete rejection of non-volatile compounds by the VMD process, despite variation in feed SGDF water quality (e.g., pH (Xie et al. 2012), TDS, temperature (Xie et al. 2013d)) affecting water flux and contaminant rejection of the FO process. In addition, it was noteworthy that the FO process achieved significant rejection of inorganic contaminants and sparingly soluble inorganic salts (Table 1). Particularly, boron rejection was 78\%by the FO process, which was similar to previous studies (Jin et al. 2011; Kim et al. 2012). Sparingly soluble $\mathrm{CaSO}_{4}$ was completely rejected whereas rejection of silica was only 33\%. Poorly rejected contaminants (e.g., silica) by the FO process could be accumulated in the draw solution because the VMD process offers near complete rejection for non-volatile compounds. Such detrimental accumulation could hamper the sustainability of the FO-VMD system in long-term operation (Xie et al. 2013a). In addition, an appropriate SGDF concentrate management should be considered because the conductivity and TDS of the SGDF concentrate increased 7 and 4.2 times, respectively, after FO-VMD hybrid process (Table 1).More importantly, the Langelier Saturation Index (LSI) of the concentrated SGDF after FO-VMD system was 0.53, which indicated the tendency of scaling formation.

High water recovery and exceptional product water quality reported here have significant implications in the SGDF-related wastewater management. This near zero-liquid-discharge FO-VMD hybrid system could effectively reclaim freshwater from SGDF, which could be beneficial to reservoir augmentation and agricultural or industrial applications. 


\section{Conclusions}

Results reported here demonstrated the feasibility of a novel hybrid forward osmosis (FO) - vacuum membrane distillation (VMD) system for water reclamation from shale gas drilling flow-back fluid (SGDF). Key operating parameters were optimized in the $\mathrm{FO}$ process. $\mathrm{KCl}$ was identified as a suitable draw solution that can offers a high water flux and an acceptable reverse solute flux. Water recovery of up to 90\% was achieved from real SGDF using a laboratory scale hybrid FO-VMD system. A notable advantage of this hybrid system was that the partial draw solution over-flow that could substantially reduce the energy consumption in VMD. Quality of the product water by the FO-VMD process was comparable to that of bottled water.

\section{Acknowledgements}

The authors would like to acknowledge financial support from the National Natural Science Foundation of China (Project No. 21176119),the National Key Basic Research

Program of China (973 Project, Project No. 2012CB932800,2009CB623402), and Australia - China Science and Research Funding: Group Mission (ACSRF06443).

\section{References}

Altaee A., Mabrouk A. and Bourouni K. (2013). A novel Forward osmosis membrane pretreatment of seawater for thermal desalination processes. Desalination326(0), 19-29.

Cath T. Y., Adams D. and Childress A. E. (2005a). Membrane contactor processes for wastewater reclamation in space II. Combined direct osmosis, osmotic distillation, and membrane distillation for treatment of metabolic wastewater. Journal of Membrane Science257(1-2), 111-9.

Cath T. Y., Adams D. and Childress A. E. (2005b). Membrane contactor processes for wastewater 
reclamation in space: II. Combined direct osmosis, osmotic distillation, and membrane distillation for treatment of metabolic wastewater. Journal of Membrane Science257(1-2), 111-9.

Cath T. Y., Childress A. E. and Elimelech M. (2006). Forward osmosis: Principles, applications, and recent developments. Journal of Membrane Science281(1-2), 70-87.

Cath T. Y., Gormly S., Beaudry E. G., Flynn M. T., Adams V. D. and Childress A. E. (2005c). Membrane contactor processes for wastewater reclamation in space Part I. Direct osmotic concentration as pretreatment for reverse osmosis. Journal of Membrane Science257(1-2), 85-98.

Chang Y., Liu X. and Christie P. (2012). Emerging Shale Gas Revolution in China. Environmental Science \& Technology46(22), 12281-2.

Dahm K. G., Guerra K. L., Xu P. and Drewes J. E. (2011). Composite Geochemical Database for Coalbed Methane Produced Water Quality in the Rocky Mountain Region. Environmental Science \& Technology45(18), 7655-63.

Ge Q., Wang P., Wan C. and Chung T.-S. (2012). Polyelectrolyte-Promoted Forward OsmosisMembrane Distillation (FO-MD) Hybrid Process for Dye Wastewater Treatment. Environmental Science \& Technology46(11), 6236-43.

He T. (2012). Forward Osmosis Process for Recovery of Highly Saline Wastewater. In: ADVANCED MEMBRANE TECHNOLOGY V: Membranes for Sustainable Water, Energy and the Environment, An ECI Conference Series, October 14-19, 201, Singapore.

Hickenbottom K. L., Hancock N. T., Hutchings N. R., Appleton E. W., Beaudry E. G., Xu P. and Cath T. Y. (2012). Forward osmosis treatment of drilling mud and fracturing wastewater from oil and gas operations. Desalination.

Jin X., She Q., Ang X. and Tang C. Y. (2012). Removal of boron and arsenic by forward osmosis membrane: Influence of membrane orientation and organic fouling. Journal of Membrane Science389, $182-7$.

Jin X., Tang C. Y., Gu Y., She Q. and Qi S. (2011). Boric Acid Permeation in Forward Osmosis Membrane Processes: Modeling, Experiments, and Implications. Environmental Science \& Technology45(6), 2323-30.

Kim C., Lee S., Shon H. K., Elimelech M. and Hong S. (2012). Boron transport in forward osmosis: Measurements, mechanisms, and comparison with reverse osmosis. Journal of Membrane Science419, 42-8.

Lay W. C. L., Zhang J., Tang C., Wang R., Liu Y. and Fane A. G. (2012). Factors affecting flux performance of forward osmosis systems. Journal of Membrane Science394, 151-68.

Liu Z., Bai H., Lee J. and Sun D. D. (2011). A low-energy forward osmosis process to produce drinking water. Energy \& Environmental Science4(7), 2582-5.

McCutcheon J. R. and Elimelech M. (2006). Influence of concentrative and dilutive internal concentration polarization on flux behavior in forward osmosis. Journal of Membrane Science284(1-2), 237-47.

McCutcheon J. R. and Elimelech M. (2007). Modeling water flux in forward osmosis: Implications for improved membrane design. AIChE Journal53(7), 1736-44.

McCutcheon J. R. and Elimelech M. (2008). Influence of membrane support layer hydrophobicity on water flux in osmotically driven membrane processes. Journal of Membrane Science318(1-2), 458-66.

McGinnis R. L., Hancock N. T., Nowosielski-Slepowron M. S. and McGurgan G. D. (2013). Pilot 
demonstration of the NH3/CO2 forward osmosis desalination process on high salinity brines. Desalination312, 67-74.

Phillip W. A., Yong J. S. and Elimelech M. (2010). Reverse Draw Solute Permeation in Forward Osmosis: Modeling and Experiments. Environmental Science and Technology44(13), 5170-6.

Phuntsho S., Vigneswaran S., Kandasamy J., Hong S., Lee S. and Shon H. K. (2012). Influence of temperature and temperature difference in the performance of forward osmosis desalination process. Journal of Membrane Science415-416(0), 734-44.

Shaffer D. L., Arias Chavez L. H., Ben-Sasson M., Romero-Vargas Castrillón S., Yip N. Y. and Elimelech M. (2013). Desalination and Reuse of High-Salinity Shale Gas Produced Water: Drivers, Technologies, and Future Directions. Environmental Science \& Technology47(17), 9569-83.

Song J., Li X. M., Figoli A., Huang H., Pan C., He T. and Jiang B. (2013). Composite hollow fiber nanofiltration membranes for recovery of glyphosate from saline wastewater. Water Research47(6), 2065-74.

Tang C. Y., She Q., Lay W. C. L., Wang R. and Fane A. G. (2010). Coupled effects of internal concentration polarization and fouling on flux behavior of forward osmosis membranes during humic acid filtration. Journal of Membrane Science354(1-2), 123-33.

Tang W. and Ng H. Y. (2008). Concentration of brine by forward osmosis: Performance and influence of membrane structure. Desalination224(1-3), 143-53.

Tong L., Zhou X. and Li H. (2013). Environmental Impacts of Shale Gas Development in China and Recommendations on Management of their Environmental Impact Assessment. In: 33rd Annual Meeting of the International Association for Impact Assessment.

Wang K. Y., Teoh M. M., Nugroho A. and Chung T.-S. (2011). Integrated forward osmosis-membrane distillation (FO-MD) hybrid system for the concentration of protein solutions. Chemical Engineering Science66(11), 2421-30.

Wei X., Zhao B., Li X.-M., Wang Z., He B.-Q., He T. and Jiang B. (2012). CF4 plasma surface modification of asymmetric hydrophilic polyethersulfone membranes for direct contact membrane distillation. Journal of Membrane Science407-408, 164-75.

Xie M., Nghiem L. D., Price W. E. and Elimelech M. (2013a). A Forward Osmosis-Membrane Distillation Hybrid Process for Direct Sewer Mining: System Performance and Limitations. Environmental Science \& Technology.DOI: 10.1021/es404056e.

Xie M., Nghiem L. D., Price W. E. and Elimelech M. (2013b). Impact of humic acid fouling on membrane performance and transport of pharmaceutically active compounds in forward osmosis. Water Research47(13), 4567-75.

Xie M., Price W. E. and Nghiem L. D. (2012). Rejection of pharmaceutically active compounds by forward osmosis: Role of solution $\mathrm{pH}$ and membrane orientation. Separation and Purification Technology93(0), 107-14.

Xie M., Price W. E., Nghiem L. D. and Elimelech M. (2013c). Effects of feed and draw solution temperature and transmembrane temperature difference on the rejection of trace organic contaminants by forward osmosis. Journal of Membrane Science438, 57-64.

Xie M., Price W. E., Nghiem L. D. and Elimelech M. (2013d). Effects of feed and draw solution temperature and transmembrane temperature difference on the rejection of trace organic contaminants by forward osmosis. Journal of Membrane Science438(0), 57-64.

Xu P. and Drewes J. E. (2006). Viability of nanofiltration and ultra-low pressure reverse osmosis 
membranes for multi-beneficial use of methane produced water. Separation and Purification Technology52(1), 67-76.

Xu P., Drewes J. E. and Heil D. (2008). Beneficial use of co-produced water through membrane treatment: technical-economic assessment. Desalination225(1-3), 139-55.

Xu Y., Peng X., Tang C. Y., Fu Q. S. and Nie S. (2010). Effect of draw solution concentration and operating conditions on forward osmosis and pressure retarded osmosis performance in a spiral wound module. Journal of Membrane Science348(1-2), 298-309.

Yen S. K., Mehnas Haja N F., Su M., Wang K. Y. and Chung T.-S. (2010). Study of draw solutes using 2-methylimidazole-based compounds in forward osmosis. Journal of Membrane Science364(1-2), 242-52.

Zhao S. and Zou L. (2011). Relating solution physicochemical properties to internal concentration polarization in forward osmosis. Journal of Membrane Science379(1-2), 459-67.

Zhao S., Zou L. and Mulcahy D. (2011). Effects of membrane orientation on process performance in forward osmosis applications. Journal of Membrane Science382(1-2), 308-15. 
412 Tables and Figures

413 Table 1: Water characteristics of raw SGDF, SGDF after different treatment steps, and bottled water from Shanghai (as a reference).

\begin{tabular}{|c|c|c|c|c|c|c|}
\hline Items & Raw SGDF & Pre-treated SGDF & $\begin{array}{l}\text { SGDF concentrate } \\
\text { after FO-VMD }\end{array}$ & $\begin{array}{c}\text { Draw solution after } \\
\text { FO-VMD }\end{array}$ & $\begin{array}{c}\text { Product water from } \\
\text { FO-VMD }\end{array}$ & $\begin{array}{l}\text { Bottled water (as a } \\
\text { reference) }\end{array}$ \\
\hline Conductivity $(\mu \mathrm{S} / \mathrm{cm})$ & 11290 & 11300 & 74400 & AUL & 5 & 43.6 \\
\hline Turbidity(NTU) & 135 & 0.18 & NA & NA & 0.07 & 0.09 \\
\hline $\mathrm{pH}$ & 7.4 & 7.40 & 8.24 & 7.89 & 7.38 & 7.88 \\
\hline Total hardness as $\mathrm{CaCO}_{3}(\mathrm{mg} / \mathrm{L})$ & 283 & 260 & 541 & NA & NA & NA \\
\hline $\mathrm{COD}(\mathrm{mg} / \mathrm{L})$ & 358 & 259.0 & 1794.0 & NA & 0.9 & 1.1 \\
\hline $\mathrm{B}(\mathrm{mg} / \mathrm{L})$ & 16.9 & 15 & 27 & 1.1 & ND & 0.02 \\
\hline $\mathrm{Ca}(\mathrm{mg} / \mathrm{L})$ & 140 & 102 & 271 & 1 & ND & 3.34 \\
\hline $\mathrm{K}(\mathrm{mg} / \mathrm{L})$ & 393 & 381 & 5180 & 90851 & 0.50 & 3.74 \\
\hline $\mathrm{Mg}(\mathrm{mg} / \mathrm{L})$ & 18 & 24.0 & 30.9 & NA & ND & 0.02 \\
\hline $\mathrm{Na}(\mathrm{mg} / \mathrm{L})$ & 2109 & 2105 & 4540 & 92 & 0.12 & 0.3 \\
\hline $\mathrm{Cl}^{-}(\mathrm{mg} / \mathrm{L})$ & 4202 & 3999 & 17632.48 & 91612.7 & 2.2 & 10.2 \\
\hline $\mathrm{SO}_{4}{ }^{2-}(\mathrm{mg} / \mathrm{L})$ & 3.2 & 3.0 & 9.1 & $<1$ & $<1$ & NA \\
\hline
\end{tabular}

414 Notes: ND - not detected; NA - not applicable; AUL: Above Upper Limit. 

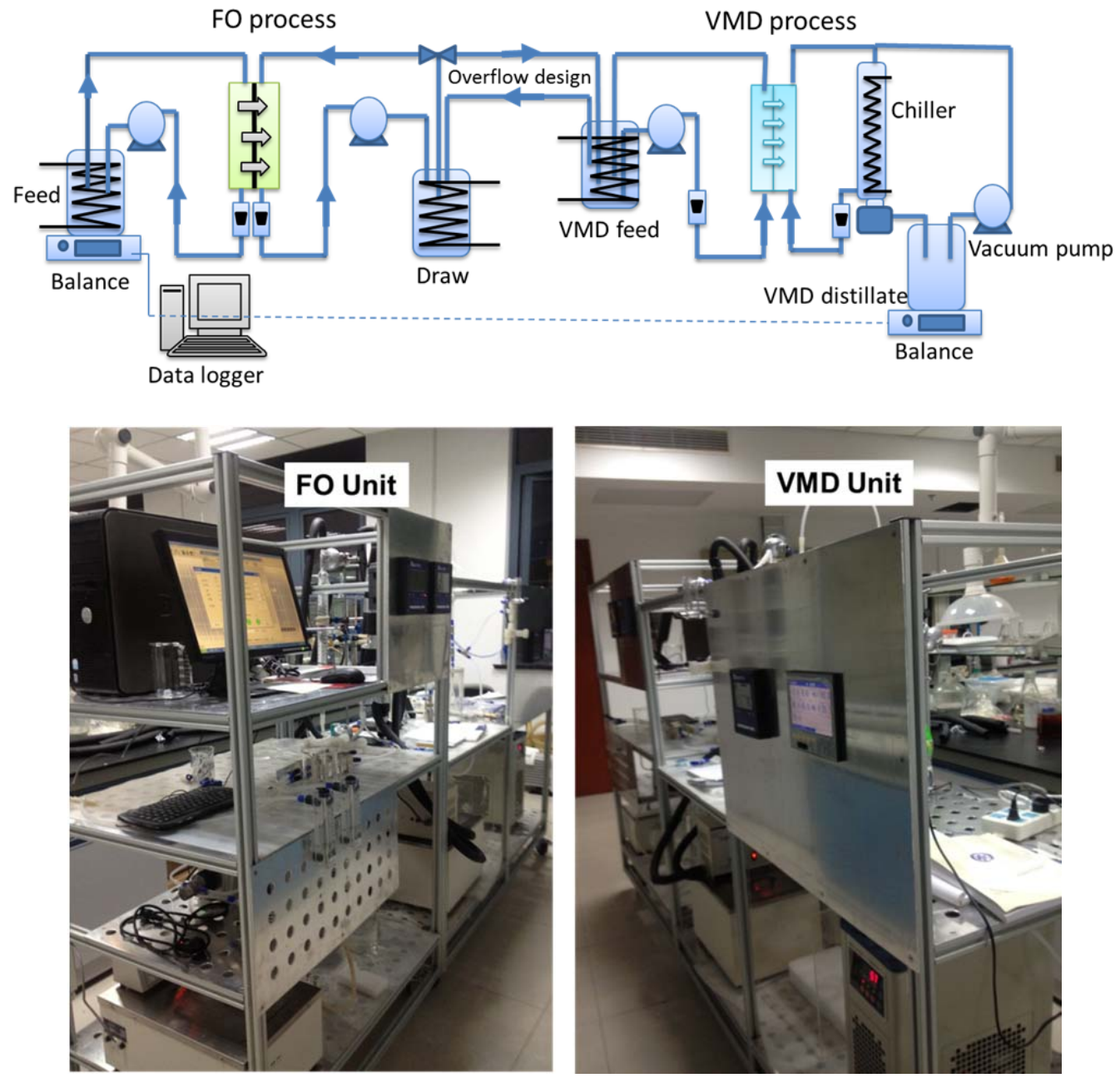

417 Figure 1: (A) schematic diagramand (B) photo of the forward osmosis (FO) - vacuum

418 membranedistillation (VMD) hybrid system. 

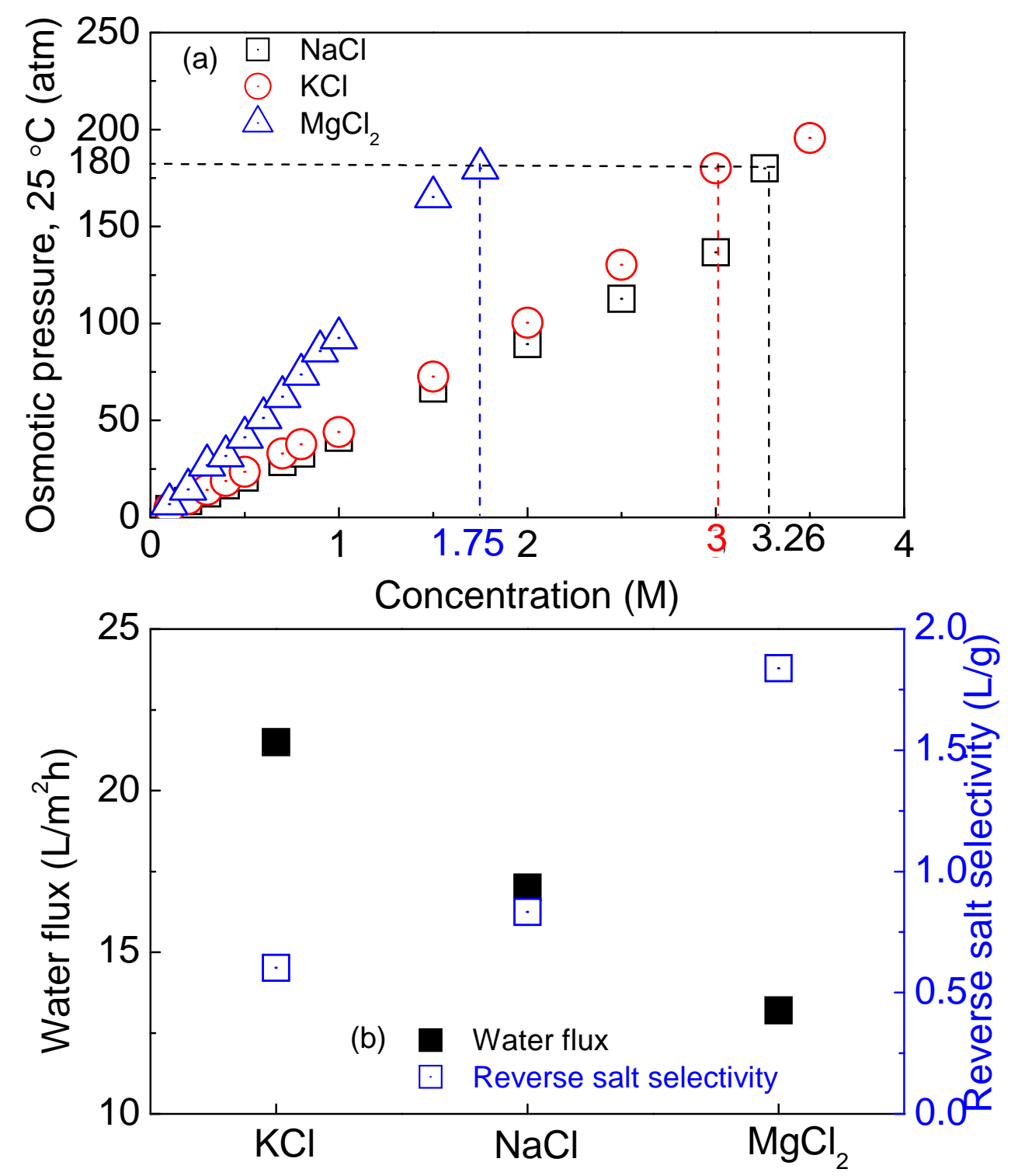

421 Figure 2: Comparison of (a)osmotic pressures,(b) water fluxes and reverse salt

422 selectivitiesusing various concentrations and types of draw solutions. 

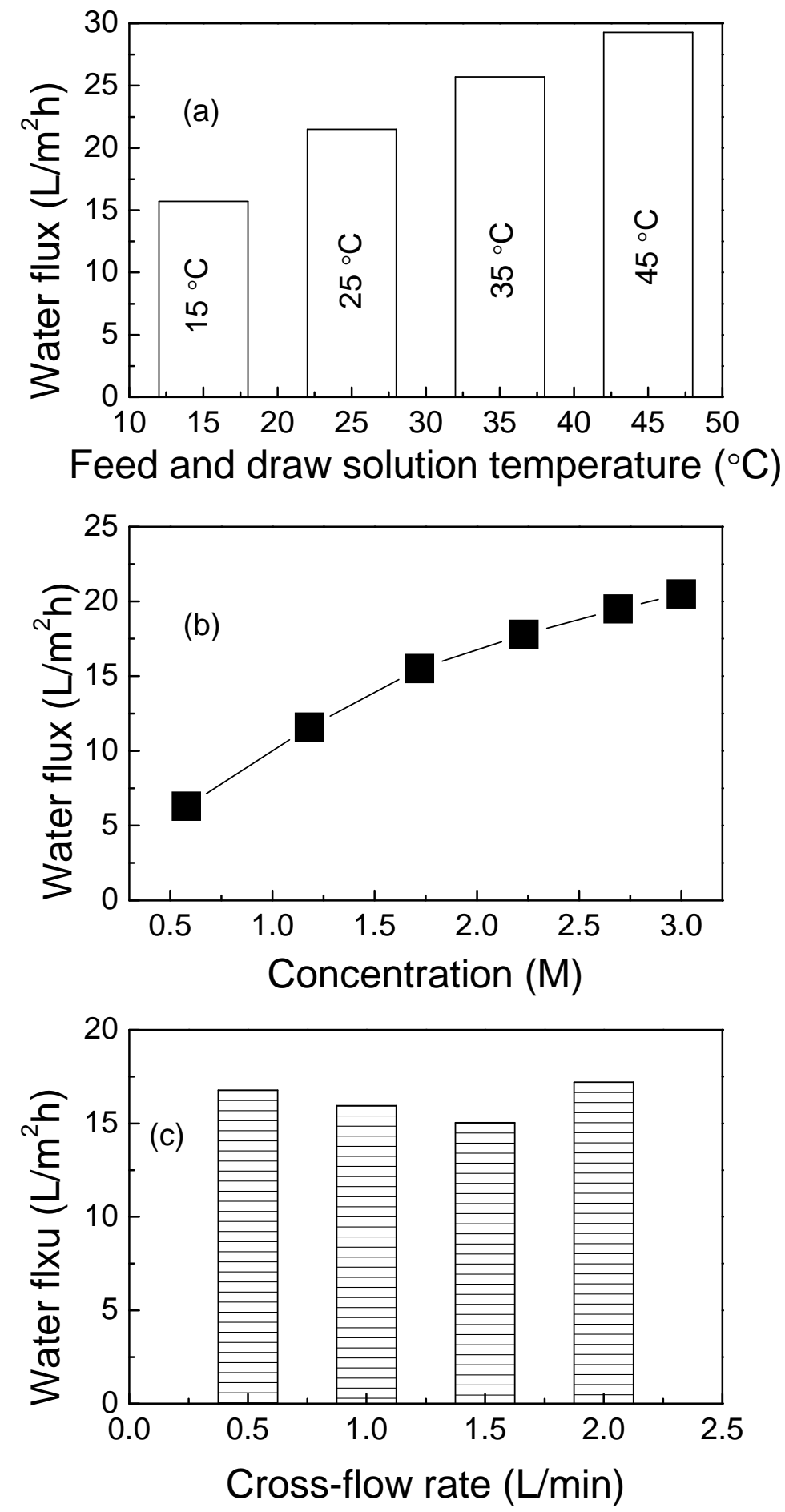

424 Figure 3: Effects of (a) feed and draw solution temperatures, (b) draw solution 425 concentration, and (c) cross-flow rates on water flux. 

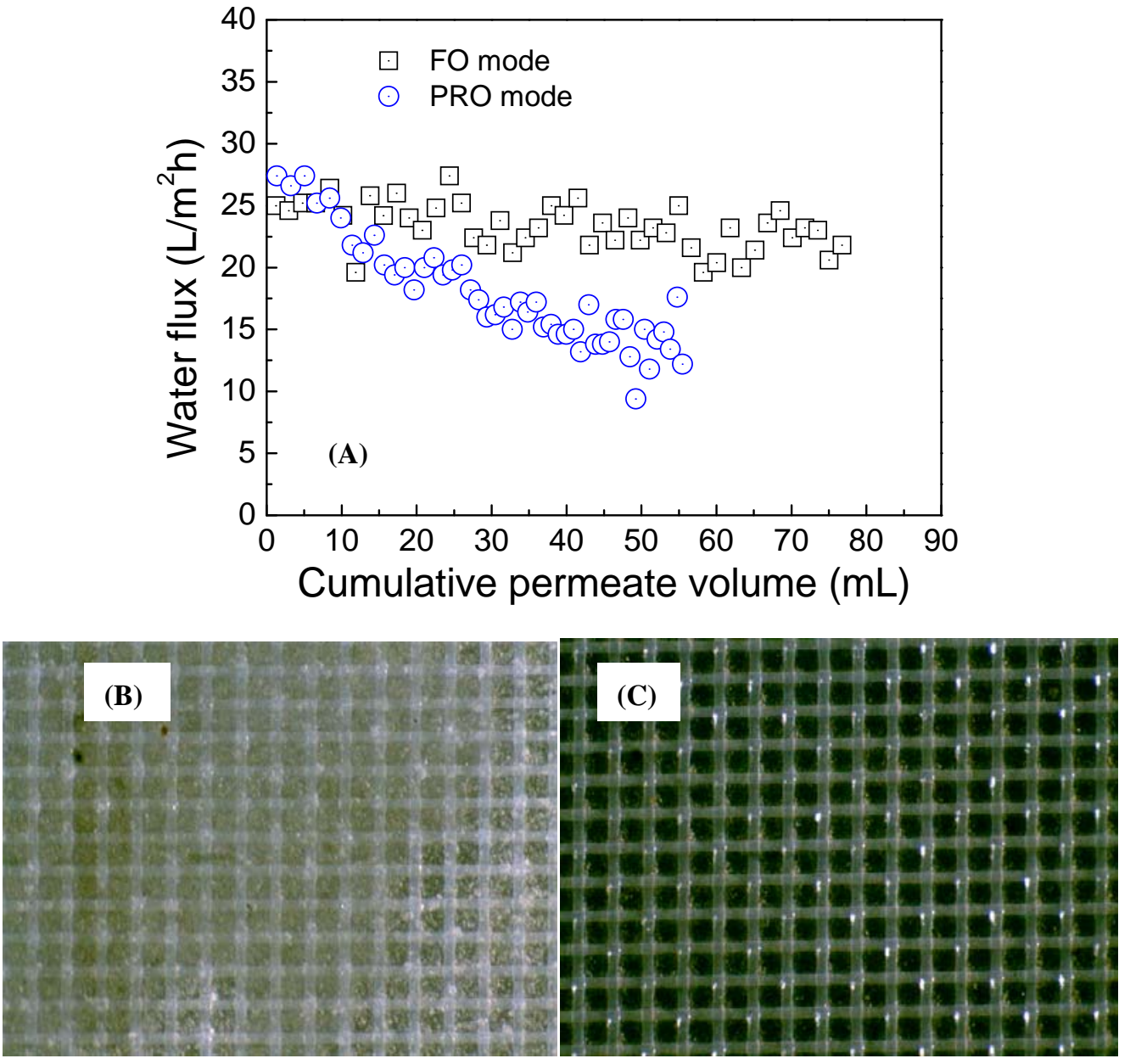

428 Figure 4: (A) Water fluxes in FO (active layer facing the feed) and PRO modes (active

429 layer facing the draw solution) and (B) microscopic observation of foulant deposited on membrane support layer (compared with the (C) clean membrane). 

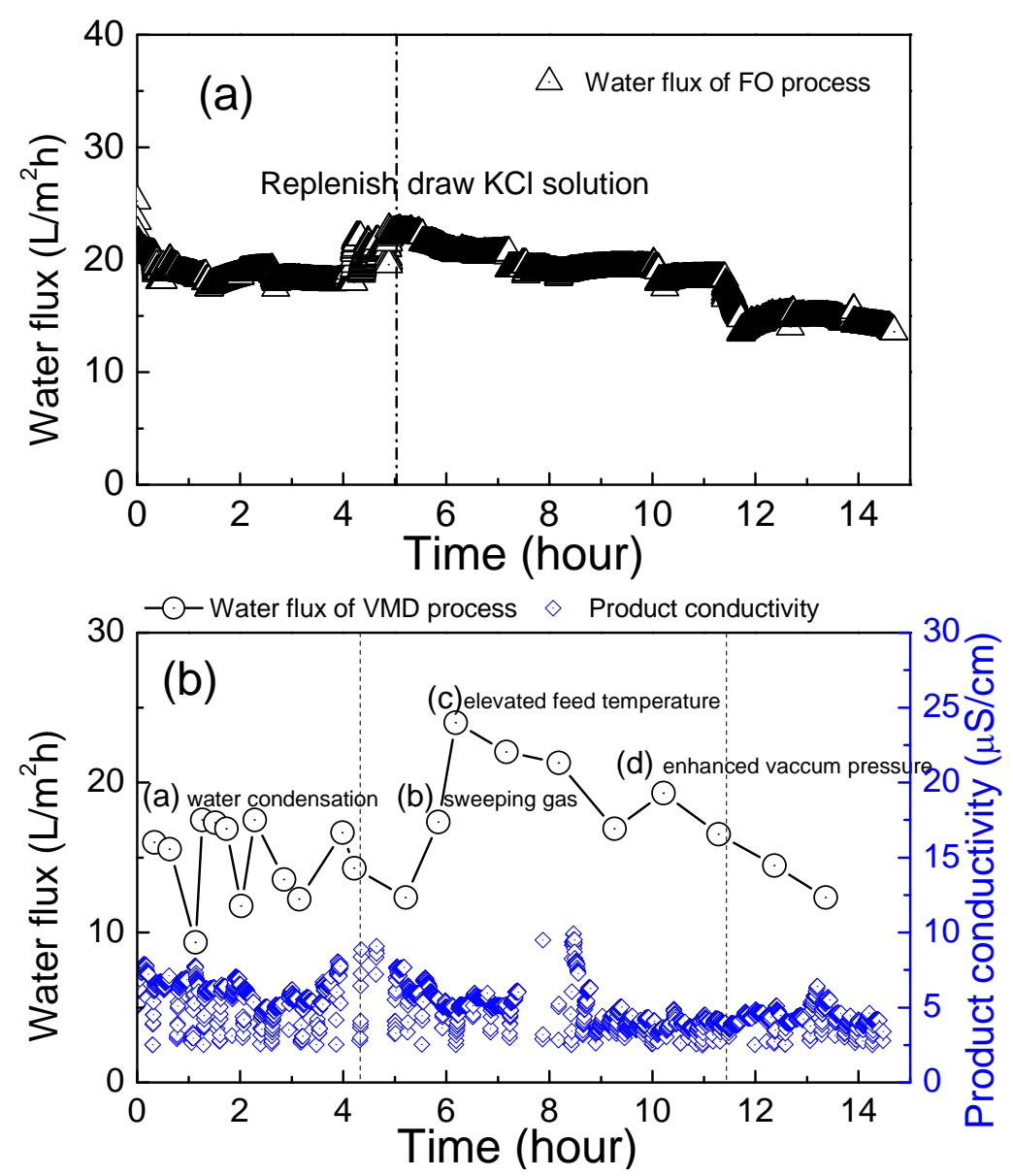

Figure 5: Bench scale hybrid FO-VMD in treating the shale gas wastewater: (a) water of $88 \%$. 